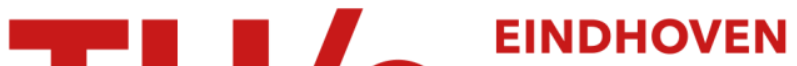 \\ UNIVERSITY OF \\ TECHNOLOGY
}

\section{Interferometric crosstalk reduction in an RSOA-based WDM passive optical network}

Citation for published version (APA):

Urban, P. J., Koonen, A. M. J., Khoe, G. D., \& Waardt, de, H. (2009). Interferometric crosstalk reduction in an RSOA-based WDM passive optical network. Journal of Lightwave Technology, 27(22), 4943-4953.

https://doi.org/10.1109/JLT.2009.2026916

DOI:

10.1109/JLT.2009.2026916

Document status and date:

Published: 01/01/2009

Document Version:

Publisher's PDF, also known as Version of Record (includes final page, issue and volume numbers)

Please check the document version of this publication:

- A submitted manuscript is the version of the article upon submission and before peer-review. There can be important differences between the submitted version and the official published version of record. People interested in the research are advised to contact the author for the final version of the publication, or visit the $\mathrm{DOI}$ to the publisher's website.

- The final author version and the galley proof are versions of the publication after peer review.

- The final published version features the final layout of the paper including the volume, issue and page numbers.

Link to publication

\section{General rights}

Copyright and moral rights for the publications made accessible in the public portal are retained by the authors and/or other copyright owners and it is a condition of accessing publications that users recognise and abide by the legal requirements associated with these rights.

- Users may download and print one copy of any publication from the public portal for the purpose of private study or research.

- You may not further distribute the material or use it for any profit-making activity or commercial gain

- You may freely distribute the URL identifying the publication in the public portal.

If the publication is distributed under the terms of Article 25fa of the Dutch Copyright Act, indicated by the "Taverne" license above, please follow below link for the End User Agreement:

www.tue.nl/taverne

Take down policy

If you believe that this document breaches copyright please contact us at:

openaccess@tue.nl

providing details and we will investigate your claim. 


\title{
Interferometric Crosstalk Reduction in an RSOA-Based WDM Passive Optical Network
}

\author{
Patryk J. Urban, Student Member, IEEE, A. M. J. Koonen, Fellow, IEEE, G. Djan Khoe, Fellow, IEEE, and
} Huug de Waardt, Member, IEEE

\begin{abstract}
Reflection and Rayleigh backscattering-induced interferometric crosstalk in a link employing a reflective semiconductor optical amplifier (RSOA) may cause significant power penalty and, thus, limit the performance of the system. In this paper, we investigate interferometric crosstalk suppression in a centralized light generation wavelength division multiplexing-passive optical network (WDM-PON) by single-tone phase modulation either by utilizing the nonlinear behavior of the RSOA at the optical network unit (ONU) or by applying an external phase modulator at the source side. 6- and 7-dB reduction in power penalty for reflection-induced crosstalk is achieved, respectively. For Rayleigh backscattering-induced crosstalk power penalty is improved with 3 and $4.5 \mathrm{~dB}$, respectively. The results show that an RSOA is very sensitive to reflections and backscattering and the tolerance to these impairments can be significantly improved by appropriate phase modulation. A comparison with advantages and disadvantages of both methods together with final recommendation is also given in the paper.
\end{abstract}

Index Terms-Backreflection, bidirectional transmission, interferometric noise, optical crosstalk, passive optical networks, Rayleigh backscattering, reflective semiconductor optical amplifier (RSOA), wavelength division multiplexing.

\section{INTRODUCTION}

$\mathbf{T}$ HE development of fiber-to-the-home (FTTH) networks is driven by bandwidth on-demand applications [1]-[4], which force the system providers to design cost-effective solutions capable of high bit rate operation. This includes network architectures [5]-[8] and novel integratable network components [9]-[11].

An RSOA is a promising cost-efficient solution for a transmitter at an ONU in a WDM-PON architecture. Nevertheless, its advantages, like integratability and wavelength-independence, are endangered by high sensitivity to backscattered or reflected power coming from, e.g., a fiber splice or a neighboring device with low return loss. This power interferes with the original continuous wavelength signal $(\mathrm{CW})$ seeding the RSOA and power instabilities arise. This so called in-band (interferometric) crosstalk causes the degradation of

Manuscript received March 31, 2009; revised June 09, 2009. First published July 07, 2009; current version published September 10, 2009. This work is part of the Freeband BBPhotonics project (http://bbphotonics.freeband.nl). Freeband is sponsored by the Dutch Government under contract BSIK 03025.

The authors are with the COBRA Research Institute, Eindhoven University of Technology (TU/e), NL-5600MB Eindhoven, The Netherlands (e-mail: p.j.urban@tue.nl; g.d.khoe@tue.nl; a.m.j.koonen@tue.nl; h.d.waardt@tue.nl; secretariaat.tte@tue.nl).

Color versions of one or more of the figures in this paper are available online at http://ieeexplore.ieee.org.

Digital Object Identifier 10.1109/JLT.2009.2026916 signal-to-noise ratio (SNR). Due to the SNR variations, power penalties may occur in the system's upstream bit error-rate (BER) performance [12]. Since coherent and incoherent optical sources can be used in a WDM-PON system, e.g., distributed feedback (DFB) lasers or a spectrally sliced broadband source [13], the phase-induced amplitude variations and resultant power penalties at the receiver are larger if the interference takes place within the coherence length of the source (coherent crosstalk) and are smaller if it happens beyond this length or an incoherent source is applied (incoherent crosstalk). However, an incoherent source provides lower output power and higher sensitivity to dispersion. Moreover, the incoherent crosstalk can still cause high power penalties as its contributions may remain coherent with each other [14].

There are some solutions to decrease the in-band crosstalk, such as additional phase modulation, polarization scrambling, low coherence source deployment [15], and time diversity between the desired and the interfering signals [16]. Recently, a novel powerful technique based on phase modulation by dithering of the RSOA bias current was proposed to fight with coherent [17], [18] and incoherent [19] crosstalk.

An access network with an RSOA has already been considered in terms of in-band crosstalk in, e.g., [20]-[22]. However, in those studies, due to the partly reflected or backscattered signal simultaneously propagating in the direction of remotely fed RSOA and the receiver the investigated crosstalk was a sum of two phenomenon, namely, the interference of downstream signal with return upstream and upstream with return downstream signal. In [23], the influence of the back-reflected signal on the performance of a saturated RSOA has been experimentally checked for the link architecture involving downstream data signal remodulated with upstream data. There, it has been also proved that the RSOA is very sensitive to backreflections. However, besides different modulation formats and proper RSOA gain adjustment, none of the known papers provided a practical solution for as effective in-band crosstalk mitigation as the techniques described here.

RSOA bias dithering is a novel method, which utilizes the amplitude-to-phase coupling in the active material of the RSOA [24], and phase modulation at the laser is a well-known method, which has been widely published [25]-[29].

In this paper, the influence of the interferometric crosstalk between the CW seed transmitted from a coherent source and the return upstream data signal in the link employing RSOA together with the two methods to mitigate such crosstalk are presented for the first time according to authors' best knowledge. Mathematical considerations supported by appropriate 


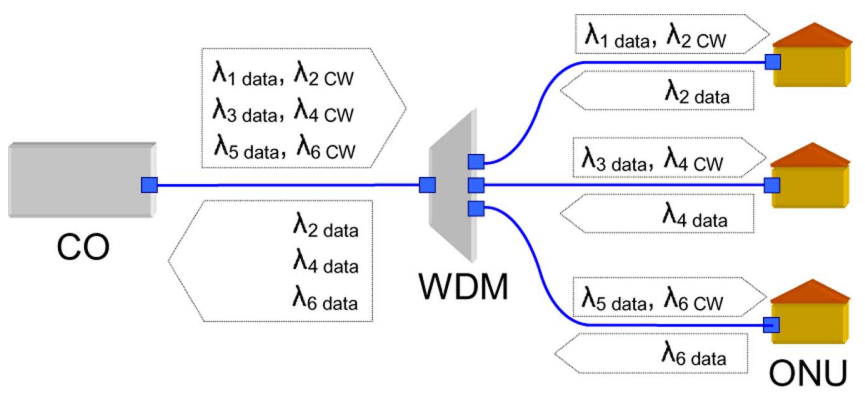

Fig. 1. Generic WDM-PON architecture; $\mathrm{CO} —$ central office; WDM-wavelength division multiplexer.

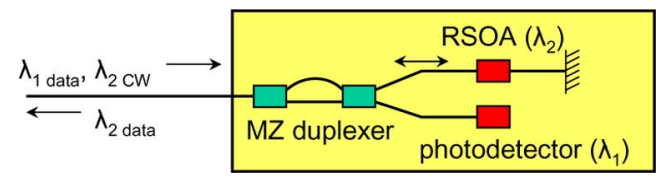

Fig. 2. ONU architecture.

measurements for both techniques are presented. A comparison of the methods and discussion on their advantages and disadvantages are given with some recommendations.

The remainder of this paper is organized as follows. Section II shows an example network architecture and the interferometric crosstalk scenario. Section III is organized in subsections corresponding to four different cases of coherent and incoherent crosstalk mitigation by RSOA bias dithering and phase modulation at a laser. It presents the mathematical background together with some conditions to be satisfied by both techniques. In a similarly divided Section IV, the experimental setup is described and measurement results are presented. Finally, a comparative discussion is provided in Section $\mathrm{V}$, and the work is summarized in Section VI.

\section{BBPHOTONICS ACCESS NETWORK}

Fig. 1 shows a general WDM-PON network architecture. The Broadband Photonics (BBPhotonics) network is an extension of a WDM-PON system which enables dynamic wavelength reconfiguration in order to provide bandwidth on-demand. The network architecture has been discussed in detail in [5] and [30] and the proof-of-principle experimental results are provided in [31]. In the BBPhotonics network, the transmission is bidirectional over a standard single mode fiber (SSMF) and the operation of the network is based on centralized light generation. This requires colorless ONUs to be placed at the user side.

In this paper, we investigate an optical link with a single ONU. Each ONU is provided with two wavelength channels: downstream data channel and downstream $\mathrm{CW}$ channel for upstream data transmission. The ONU contains a Mach-Zehnder (MZ) duplexer which demultiplexes a modulated signal and a CW signal at its two outputs. As shown in Fig. 2, a photodetector is connected to the upper output and the RSOA to the lower output of the MZ. The CW signal is amplified and intensity modulated in the RSOA ( $1.25 \mathrm{Gbit} / \mathrm{s}$, not-return to zero on/off keying, NRZ OOK). It is reflected at the end-facet of the RSOA and sent back to the $\mathrm{CO}$ with upstream data.

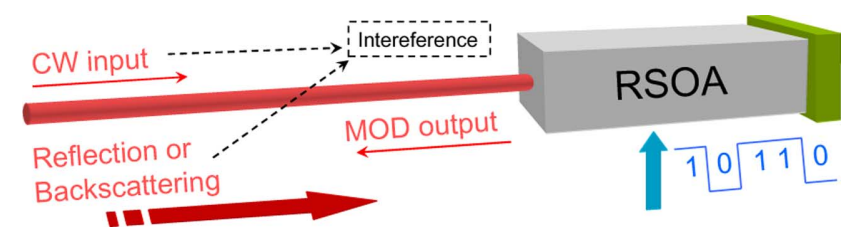

Fig. 3. RSOA-based drop link with crosstalk.

The interferometric crosstalk may arise in such a drop link, if, e.g., the WDM node to which it is connected has low return loss. It may also happen due to the Rayleigh backscattering (RBS) power accumulated over the complete CO-ONU link, as it is an in-band type of crosstalk and cannot be filtered by an optical filter.

The interference scenario which is investigated in this paper is schematically shown in Fig. 3. The CW signal enters the RSOA. It is amplified and intensity modulated. The output modulated signal propagates along the same fiber in the opposite direction with respect to the input $\mathrm{CW}$ light. Such signal may encounter a reflection and some power may travel back to the RSOA. A similar situation is when a long fiber, i.e., $20-30 \mathrm{~km}$, is applied and some power may feed back the RSOA due to RBS phenomenon. Since reflected/backscattered signals, further denoted as interferers, and CW input signal travel along the same fiber in the same direction they interfere with each other. The phase relation between interfering beams remains stable within the coherence length of the source in case of a reflected interferer, and for an RBS-induced interferer this relation has a random nature. Therefore, the former case causes coherent crosstalk and the latter case incoherent crosstalk.

\section{THEORY}

In order to reduce the interferometric crosstalk we apply methods, which are based on spectral broadening. Optical power of a spectrally broadened signal is spread over larger optical bandwidth, which means that the coherence length (or coherence time) of the light is reduced. The relation of coherence length and spectral width is described by (1)

$$
L_{c}=\frac{c}{n} \frac{1}{\pi \Delta \lambda}
$$

where $c$ is the speed of light in vacuum, $n$ is the refractive index and $\Delta \lambda$ is the spectral linewidth. The spectrum is broadened by phase modulation, which is introduced by chirping in the RSOA, further denoted as RSOA bias dithering, or by phase modulation at the laser.

\section{A. Coherent Crosstalk and RSOA Bias Dithering}

We investigate the conditions for RSOA bias dithering, which have to be satisfied in order to suppress the crosstalk caused by a reflection feeding back the RSOA.

The electric field at the output of the laser is given by (2)

$$
E(t)=\sqrt{P(t)} e^{j\left[\Omega_{0} t+\varphi(t)\right]}
$$

where $P(t)$ is the output laser power, $\Omega_{0}$ is the optical carrier frequency and $\varphi(t)$ is the laser phase noise. The laser phase 


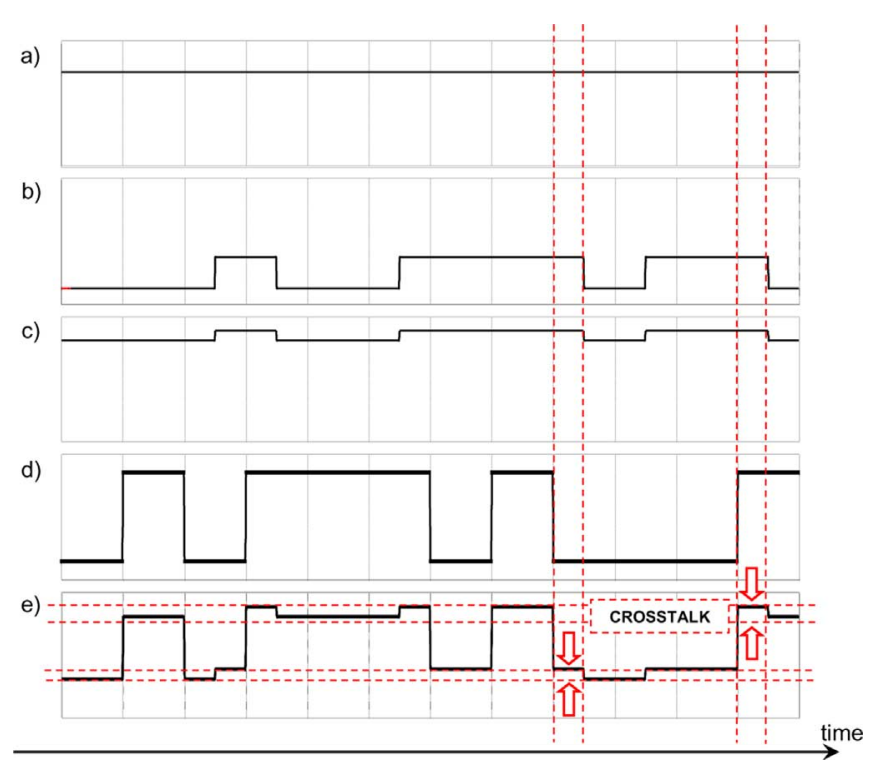

Fig. 4. Mathematical model of crosstalk in an RSOA link: photocurrent [according to (10)] of (a) the CW input signal, (b) the interferer, (c) the total input signal, (d) the PRBS generator output current, (e) the photocurrent [according to (10)]) of RSOA output signal.

noise is much smaller than the phase changes induced by modulation. If we assume an output power constant in time the above equation can be written as follows:

$$
E(t)=\sqrt{P_{0}} e^{j \Omega_{0} t}
$$

where $P_{0}$ is the constant laser output power as shown in Fig. 4(a). Assuming negligible nonlinear interaction in the fiber, the field which propagates from the laser towards the RSOA at the output of the fiber is described by (4)

$$
E_{\text {in }}(t)=\sqrt{\Psi_{0} \Psi_{1} P_{0}} e^{j \Omega_{0} t}
$$

where $\Psi_{0}$ indicates the fraction of the power remaining after the attenuation of the link between laser output and the point of reflection (including the attenuation at the point of reflection) and $\Psi_{1}$ denotes fraction of the power remaining after the attenuation of the fiber on the distance between the point of reflection and the RSOA.

The light is amplitude modulated in the RSOA. Due to the swing of the current, which induces the amplitude modulation, the carrier density changes accordingly. This causes the variations of the refractive index of the active material in the RSOA. Consequently, the phase of the light is also changed (modulated). As a result, the output field is described by the following equation:

$$
E(t)=\sqrt{\Psi_{0} \Psi_{1} G(t) P_{0}} e^{j\left[\Omega_{0} t+\phi_{r}(t)\right]}
$$

where $G(t)$ is the modulated linear gain of the amplifier. $\phi_{r}(t)$ represents the changes in optical phase induced by amplitude-to-phase coupling in the RSOA (chirp).
Due to, e.g., very low return loss of a connector (point of reflection) part of the output signal returns to the RSOA. At the input of the RSOA such reflected beam is represented by (6) and plotted in Fig. 4(b)

$$
E_{\text {feedback }}(t)=\sqrt{\Psi_{0} \Psi_{1} \Psi_{2} G(t) P_{0}} e^{j\left[\Omega_{0} t+\phi_{r}(t)\right]}
$$

where $\Psi_{2}$ represents the fraction of the power remaining after the total return loss which includes fiber attenuation on the distance from the RSOA to the point of reflection, return loss at the point of reflection and the fiber attenuation on the distance from the point of reflection to the RSOA. The two signals represented by (4) (delayed) and (6) are coupled together at the RSOA input, (7) and the complete input light is described by (8), Fig. 4(c)

$$
\begin{aligned}
E_{\text {total,in }}(t)= & E_{\text {in }}(t-\tau)+E_{\text {feedback }}(t) \\
E_{\text {total,in }}(t)= & \sqrt{\Psi_{0} \Psi_{1} P_{0}} e^{j \Omega_{0}(t-\tau)} \\
& +\sqrt{\Psi_{0} \Psi_{1} \Psi_{2} G(t) P_{0}} e^{j\left[\Omega_{0} t+\phi_{r}(t)\right]}
\end{aligned}
$$

where $\tau$ is the time difference (delay) between the unmodulated signal and the interferer.

Because the two signals have the same nominal wavelength and propagate in the same direction, they interfere. Subsequently, such disturbed signal is amplitude modulated by a PRBS signal [Fig. 4(d)] and its phase is also changed due to the same phenomenon as before. The final output electric field is shown schematically in Fig. 4(e) and is described by (9)

$$
\begin{aligned}
& E_{\text {out }}(t)=\sqrt{\Psi_{0} \Psi_{1} G(t-\tau) P_{0}} e^{j\left[\Omega_{0}(t-\tau)+\phi_{r}(t-\tau)\right]} \\
& \quad+\sqrt{\Psi_{0} \Psi_{1} \Psi_{2} G(t) G(t-\tau) P_{0}} e^{j\left[\Omega_{0} t+\phi_{r}(t)+\phi_{r}(t-\tau)\right]} .
\end{aligned}
$$

In general, the photocurrent generated at the photodetector after neglecting shot noise and thermal noise can be written as follows:

$$
I=R[|E(t)|]^{2}
$$

where $R$ is the photodetector responsivity given in $A / W$. The photocurrent generated after photodetection of the signal represented by (9) is, therefore, given by (11)

$$
i_{s}(t)+i_{n}(t)=R\left[\left|E_{\text {out }}(t)\right|\right]^{2} .
$$

The term $i_{s}(t)$ represents the amplitude-modulated desired signal, whereas the noise term $i_{n}(t)$ is the result of interferometric crosstalk indicated by arrows in Fig. 4(e). After the introduction of the right side of the (9) into (11), we obtain the expressions for the signal (assuming $\Psi_{2} \ll \Psi_{1}$ ) and noise current

$$
\begin{aligned}
i_{s}(t) & =R \Psi_{0} \Psi_{1} G(t-\tau) P_{0}\left[1+\Psi_{2} G(t)\right] \\
& \cong R \Psi_{0} \Psi_{1} G(t-\tau) P_{0} \\
i_{n}(t) & =2 R \Psi_{0} \Psi_{1} G(t-\tau) P_{0} \sqrt{\Psi_{2} G(t)} \cos \left[-\Omega_{0} \tau-\phi_{r}(t)\right]
\end{aligned}
$$




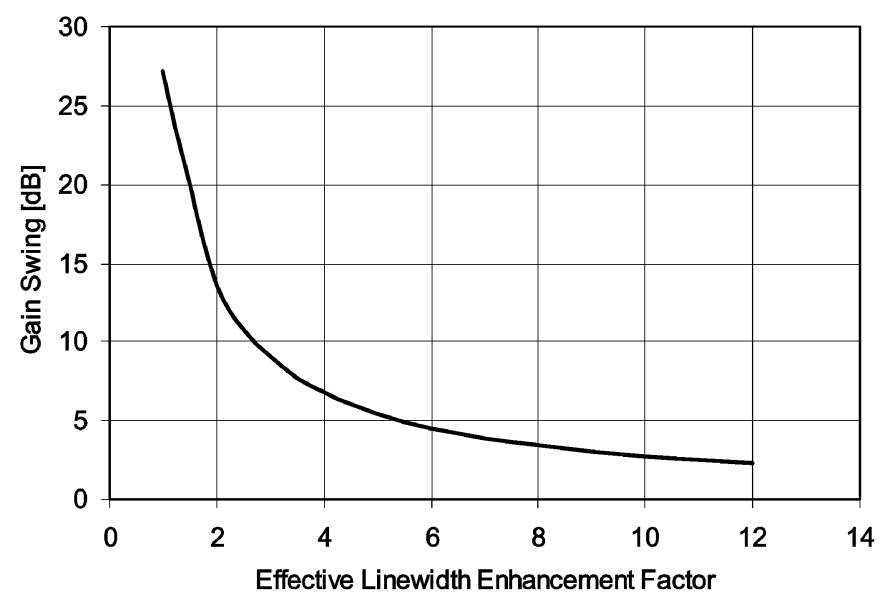

Fig. 5. Gain swing required for $\pi$ phase shift in function of linewidth enhancement factor for different data amplitudes.

A common figure of merit used for analysing the chirp performance is the alpha parameter (linewidth enhancement factor, LEF) given by the following equation [32]:

$$
\alpha_{\mathrm{eff}}=-2 \frac{\Delta \phi_{r}}{\ln (\Delta G)} .
$$

We use here the effective $\alpha$-factor, which is defined as the phase to gain changes coupling factor measured at the output of the RSOA. The phase deviation $\Delta \phi_{r}$ can be obtained from the (14)

$$
\Delta \phi_{r}=\frac{-\alpha_{\mathrm{eff}}}{2} \ln (\Delta G) \text {. }
$$

If the phase deviation $\Delta \phi_{r}$ caused by gain change $\Delta G$ is equal to or higher than $\pi$ the term on the right side of (13) fully oscillates around 0 [27]

$$
\left|\Delta \phi_{r}\right| \geq \pi
$$

After combining (15) and (16) we obtain the following:

$$
\left|\frac{-\alpha_{\text {eff }}}{2} \ln (\Delta G)\right| \geq \pi
$$

If the term on the right side of the (13) oscillates at a frequency which is out of the receiver bandwidth it is averaged out in the stopband by the low-pass filter of the receiver. That way the interferometric noise is mitigated by superposition of high frequency modulation [33]. To satisfy these two conditions we need to induce large enough amplitude-to-phase coupling at a frequency higher than the data rate, which can be achieved by applying an additional current (dither) to the RSOA with appropriate amplitude and frequency.

Fig. 5 shows the relation of the gain swing $\Delta G$ versus LEF based on (17). The gain swing has to be higher for the materials with lower LEF in order to produce sufficient phase deviation. For the case of high values of LEF the phase is strongly modulated by the data current. However, in such a situation the phase modulation is performed at a frequency which is within the electrical bandwidth of the data signal and cannot be filtered out by the low-pass filter at the receiver.

For commercially available devices, LEF varies from 2-3 to 4-8 for MQW- and bulk material-based RSOAs, respectively
[34]. At the same time, the electrical bandwidth is lower for RSOA with bulk material. Therefore, the required dithering amplitude has to be considered based on the type of RSOA material (value of LEF), its maximum electrical bandwidth, the bitrate and the dithering frequency. In general, if the modulation bandwidth is low and LEF is high, the amplitude and the frequency of dithering signal should be lower than in the case of a device with a larger bandwidth and lower LEF.

\section{B. Incoherent Crosstalk and RSOA Bias Dithering}

A single reflection in the link as described in the previous Section produces coherent crosstalk under the condition that the light beams interact within the coherence length. However, if the interferer rises up as a results of multiple discrete reflections, like RBS, the relation between the crosstalk signal and the useful signal is incoherent. One can expect that the power penalty in such a situation is smaller than when both beams are highly coherent.

In the coherent crosstalk, the phase of the reflected beam is very important. It can happen that the interfering beams meet in phase and produce large amplitude deviation; thus, the phase shift required to mitigate the crosstalk is higher. On the other hand, it can also happen that the beams meet out of phase and no amplitude-to-phase coupling is needed, since there is no crosstalk-induced amplitude variation. In the case of incoherent crosstalk it is impossible to describe exactly the phase relation and the interference between the beams is completely random. Hence, for the mathematical model the worst case condition is taken, which means that the beams meet in phase and interfere constructively. The same assumption was taken for the model with coherent crosstalk to find the largest phase shift needed. Therefore, the relation of the gain swing versus LEF (Section III-A) remains valid for the case of incoherent crosstalk.

\section{Coherent Crosstalk and External Phase Modulation}

Another method to introduce phase modulation is to apply an external phase modulator at the laser. Here, we mathematically define the conditions for such phase modulation, which have to be satisfied in order to suppress the crosstalk.

The electric field at the output of the laser is given by (3). Next, this signal enters the phase modulator which we introduce here as an ideal device (no insertion loss). The output of the modulator is described by the following equation:

$$
E(t)=\sqrt{P_{0}} e^{j\left[\Omega_{0} t+\phi_{p}(t)\right]}
$$

where $\phi_{p}$ represents the modulated phase of the optical carrier. If we apply the same procedure as for in (4)-(11) to the signal given by the above formula, we obtain an expression for the interferometric noise component of the photocurrent

$$
\begin{aligned}
i_{n}(t) & =2 R \Psi_{0} \Psi_{1} G(t-\tau) P_{0} \sqrt{\Psi_{2} G(t)} f(t) \\
f(t) & =\cos \left[-\Omega_{0} \tau+\phi_{p}(t-\tau)-\phi_{p}(t)-\phi_{r}(t)\right] .
\end{aligned}
$$

If a sine-shape signal is applied to modulate the phase at the source, the expression describing phase deviation at the phase modulator is given as follows:

$$
\phi_{p}(t)=M \sin \left(2 \pi f_{p} t\right)
$$




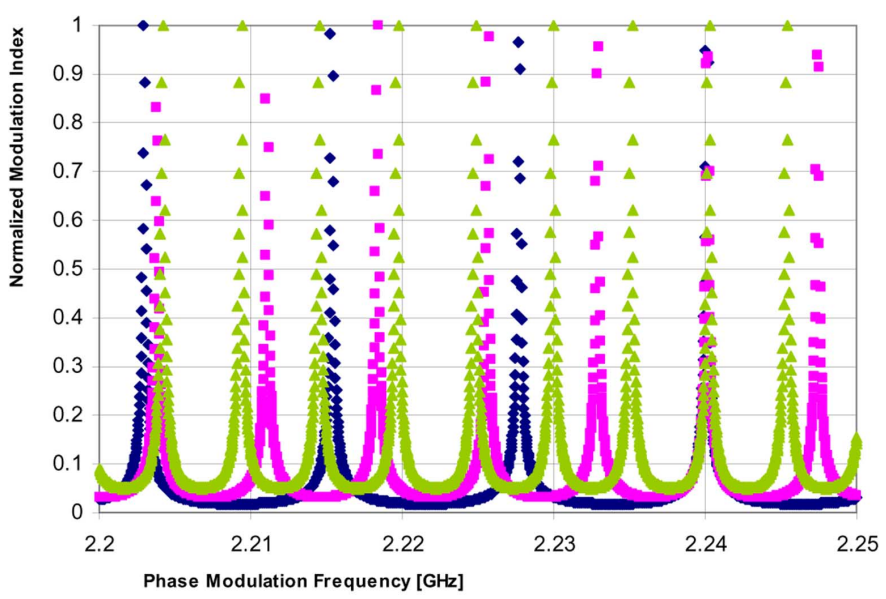

Fig. 6. Required phase modulation index in function of the frequency of phase modulation.

where $M$ is the modulation index and $f_{p}$ is the frequency of the phase modulating signal. When the above is taken into account together with the assumption that the phase changes induced in the RSOA are negligible with respect to the external phase modulation, we can modify the (19) to the following:

$$
\begin{aligned}
i_{n}(t) & =2 R \Psi_{0} \Psi_{1} G(t-\tau) P_{0} \sqrt{\Psi_{2} G(t)} f(t) \\
f(t) & =\cos \left\{-\Omega_{0} \tau-2 M \sin \left(\pi f_{p} \tau\right) \cos \left[\pi f_{p}(2 t-\tau)\right]\right\} .
\end{aligned}
$$

Applying the same condition as in (16) to the phase deviation induced by the phase modulator gives the formula below

$$
\left|-2 M \sin \left(\pi f_{p} \tau\right)\right| \geq \pi .
$$

The result after solving (22) shows the relation of modulation index to the frequency of phase modulating signal, Fig. 6 (RSOA $L E F=0$ ). This curve shows the minimum phase modulation index to be applied in order to have phase deviation equal to or higher than $\pi$. The results show strong periodic dependence, and the interval between the peaks on the graph corresponds to the delay time between the interfering beams, (23)

$$
\Delta f=\frac{1}{\tau}
$$

In (21), amplitude-to-phase coupling in the RSOA was neglected, as there was no bias dithering applied. However, the data current itself which is applied to the RSOA causes some amplitude-to-phase coupling $(L E F \neq 0)$. Putting this phenomenon back into consideration results in a modification of (22) as follows:

$$
\left|-2 M \sin \left(\pi f_{p} \tau\right)-\frac{\alpha_{\text {eff }}}{2} \ln \right| \Delta G|| \geq \pi
$$

The results for some example LEF values are given in Fig. 6. The interval between the peaks changes with respect to the case when LEF is equal to 0 (no amplitude-to-phase coupling), which is due to the fact that the phase delay between the interfering beams is different for each case because of the phase shifting in the RSOA.

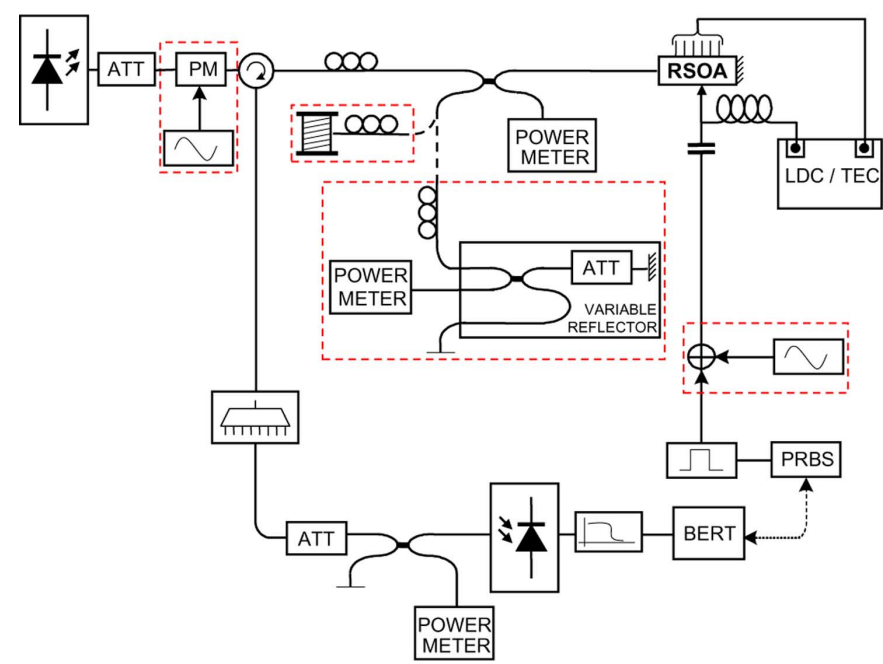

Fig. 7. Experimental setup: ATT—variable attenuator; PM—phase modulator; LDC—-laser diode controller; TEC — temperature controller; PRBS—pseudorandom bit sequence; BERT — bit error-rate tester.

In practice, the relation depicted in Fig. 6 will be applicable only within the coherence length of the laser and it implies additional restriction for the phase modulation frequency with respect to first condition given in (16).

Beyond the coherence length this phase relation is unpredictable and the beams interfere randomly causing less interferometric noise than within the coherence length, and, therefore, only condition (16) remains applicable. This theory has been verified experimentally in Section IV-C.

\section{Incoherent Crosstalk and External Phase Modulation}

Here, the mathematical model is the same as for the coherent crosstalk with external modulation (Section III-C). However, since the light coming back to the RSOA is incoherent and the beams interfere randomly, the delay included in the model for coherent crosstalk cannot be defined. Due to that, the periodic relation presented in Fig. 6 is not applicable here and the exact quantitative requirement for phase modulation index $M$ cannot be given.

\section{EXPERIMENTS}

The setup which is used for measurements is shown in Fig. 7. A CW carrier is transmitted from the external cavity laser (linewidth $<15 \mathrm{MHz}$ ) through the variable attenuator, the circulator, the polarization controller (polarization state adjusted for the highest output power) and the 3-dB coupler into the MQW-based RSOA. The 3-dB coupler enables power monitoring. It also enables the addition of reflected or backscattered light only in the direction of the RSOA.

The RSOA is temperature controlled and it is biased with $27 \mathrm{~mA}$. The transparency current is $9 \mathrm{~mA}$ and the RF current swing used for data modulation is set to $20 \mathrm{~mA}\left(2^{31}-1\right.$ PRBS at $1.25 \mathrm{Gbit} / \mathrm{s})$.

The output power is divided in a 3-dB coupler and part of it goes through the polarization controller either into the variable reflector, where the return loss can be adjusted, or into the $25-\mathrm{km}$ SSMF to induce the RBS. The reflected/backscattered power 
passes again through the $3-\mathrm{dB}$ coupler into the same fiber where the original CW light is transmitted towards the RSOA. The CW light and the reflected light interfere introducing interferometric noise. This interference is coherent when variable reflector is used and incoherent when the SSMF is used instead. The final modulated signal passes the circulator where it is directed to the AWG to filter out the ASE noise ( $0.8 \mathrm{~nm}$ bandwidth). Next, in order to measure the BER versus received optical power (ROP), the received optical power is adjusted with a variable attenuator and monitored by a power meter attached to one of the outputs of the $3 \mathrm{~dB}$ coupler. The other output sends light into a 1.25-Gbit/s receiver with limiting amplifier followed by a BER measurement testset (BERT). The eye diagrams are recorded with an O-E lightwave converter with $800-\mathrm{MHz}$ low-pass filter which clearly show the influence of crosstalk with and without additional modulation.

The utilization of a circulator prevents the modulated output signal of the RSOA to be influenced by the reflected or backscattered power of the $\mathrm{CW}$ seed.

The RSOA input power is kept at $-20 \mathrm{dBm}$ and the linear fiber-to-fiber gain of the RSOA is $20 \mathrm{~dB}$ [35]. The 1.25-Gbit/s receiver sensitivity is $-22 \mathrm{dBm}\left(\mathrm{BeR}=10^{-12}\right)$. However, in the following experiments the reference curve represents the results of the measurement taken in the setup as given in Fig. 7 without any feedback, RSOA bias dithering or external phase modulation. The reference signal is modulated in the RSOA, and, therefore, the receiver sensitivity is decreased to $-21.5 \mathrm{dBm}$ at $\mathrm{BeR}=10^{-9}$ (around $-20 \mathrm{dBm}$ at $B E R=10^{-12}$ ). The direct reason for this $1.5 \mathrm{~dB}$ reduction is the performance of the RSOA as a modulator (extinction ratio is $<8 \mathrm{~dB}$, modulation bandwidth is $1.5 \mathrm{GHz}$, residual ASE noise after $0.8 \mathrm{~nm}$ filter).

As described in Section III, two methods are used to mitigate the interferometric crosstalk, namely RSOA bias dithering and external phase modulation. The first technique requires an extra RF signal generator used to dither the bias of the RSOA. This signal is combined with the RF signal used for data modulation and goes through the bias tee into the RSOA. For the second technique, an extra phase modulator at the output of the laser is used. In this case, the output of the dithering signal generator is connected to the phase modulator.

In both methods, the frequency $(2.5 \mathrm{GHz})$ of the phase modulating signal is situated out of the receiver bandwidth so the low-pass filter at the receiver suppresses the superposed interferometric noise products at higher frequencies.

\section{A. Coherent Crosstalk and RSOA Bias Dithering}

First, we induce coherent crosstalk by applying a variable reflector and bias dithering by adding a sine-wave signal to the bias of the RSOA as indicated in Fig. 7. The return loss is adjusted in the variable reflector, and the total return loss which is used to calculate signal-to-crosstalk ratio (SCR) includes also the losses in the $3-\mathrm{dB}$ coupler and all the connectors.

The dithering frequency $(2.5 \mathrm{GHz})$ is equal to twice the bitrate. This yields a shift of the crosstalk products sufficiently far above the baseband data spectrum. It allows the suppression of interferometric crosstalk in the stopband of the low-pass filter in the receiver. The required amplitude of the dithering is high due

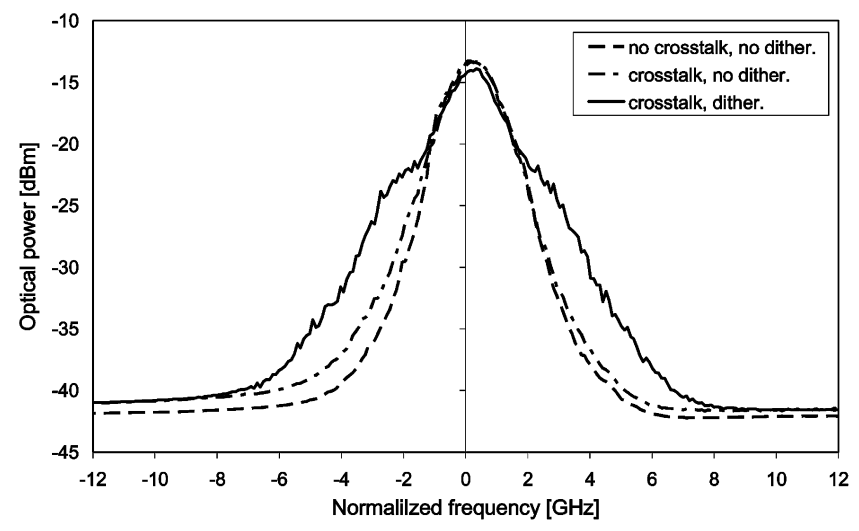

Fig. 8. RSOA output spectra.

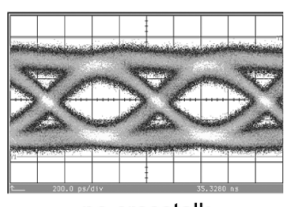

no crosstalk

no bias dithering

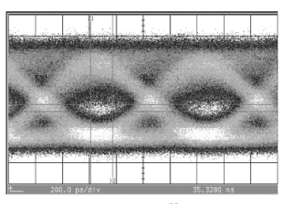

crosstalk

no bias dithering

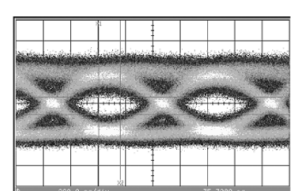

crosstalk

bias dithering
Fig. 9. Example eye diagrams for $S C R=11 \mathrm{~dB}$.

to the low value of the linewidth enhancement factor (around 2-3 for the applied MQW-RSOA).

The spectrum of the output signal of the RSOA, Fig. 8, is broader when dithering is applied on the bias. According to (1), the coherence length of such light becomes shorter, and, thus, the phase relation between the interfering beams is weaker. The receiver sensitivity penalty caused by RSOA bias dithering (measured in the absence of interferometric crosstalk) is lower than $0.2 \mathrm{~dB}$ at $B E R=10^{-9}$, and, therefore, it is neglected further in this work.

Fig. 9 shows the degradation of the eye diagram for the signal-to-crosstalk ratio (SCR) equal to $11 \mathrm{~dB}$. The standard deviation of the "1"-level is significantly reduced after applying the dithering on the RSOA bias. At the same time the eye-opening improves, although the signal amplitude decreases. This, in general, improves the SNR and the BER.

Power penalty at BER equal to $10^{-9}$ is measured for different values of SCR, Fig. 10. It can be seen that with this technique the power penalty is remarkably reduced even for very low values of SCR (6-dB improvement for SCR equal to $18.5 \mathrm{~dB}$ ). The error floor is eliminated which shows that even better BER values can be achieved.

\section{B. Incoherent Crosstalk and RSOA Bias Dithering}

The incoherent crosstalk is a result of interference between the $\mathrm{CW}$ beam and the RBS power accumulated over $25-\mathrm{km}$ SMF. In our setup, it results in a SCR equal to $18.5 \mathrm{~dB}$ and it introduces around 5-dB power penalty and an error floor (at $\mathrm{BeR}=3 \cdot 10^{-9}$ ), Fig. 11 .

The spectrum of the reference signal at the output of the RSOA, where no dithering is applied and no RBS is present, is shown in Fig. 12 together with the spectrum of the RBS-distorted signal. As it can be seen besides the RBS there is also Brillouin backscattering. However, the latter has much lower power 


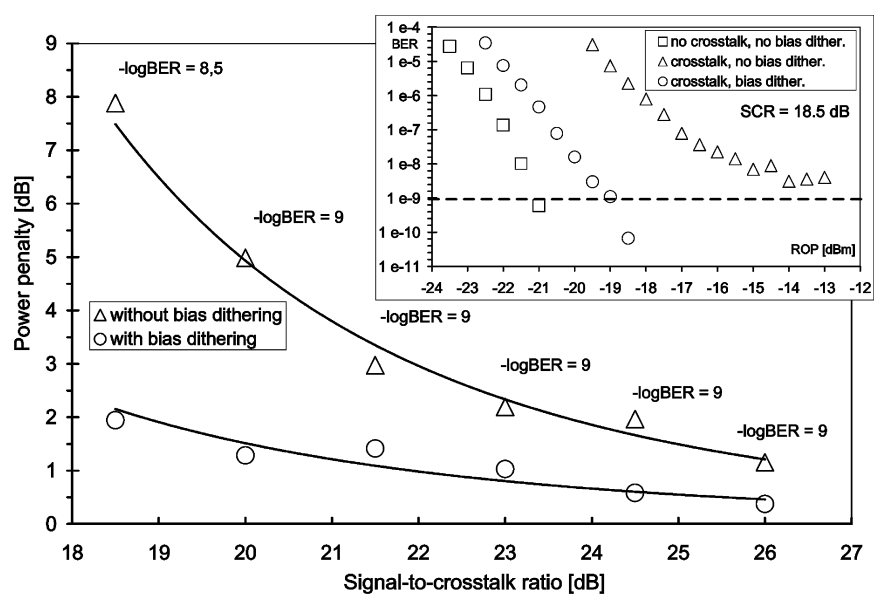

Fig. 10. Coherent crosstalk-induced power penalties and with and without RSOA bias dithering.

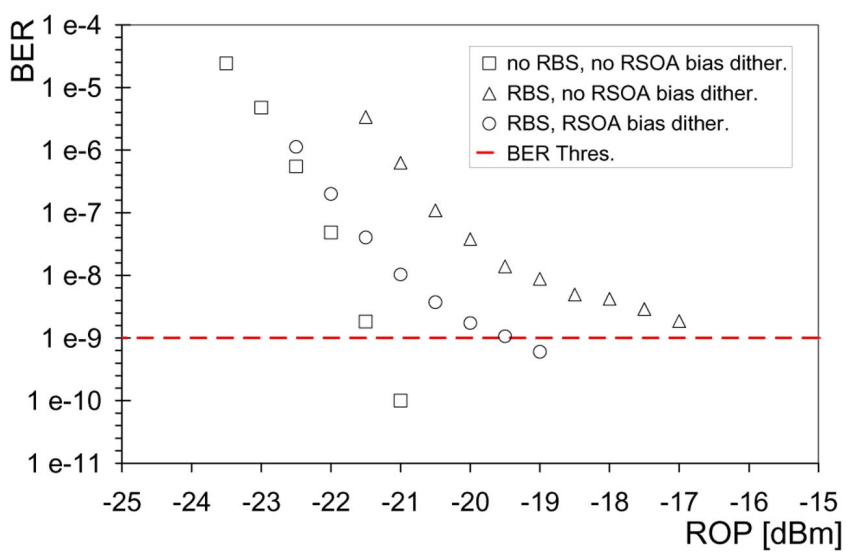

Fig. 11. BER results with and without RSOA bias dithering in case of incoherent crosstalk.

than the former, and, thus, it does not influence the useful signal. After applying the bias dithering at the RSOA the spectrum of the output signal broadens, Fig. 12, and the power penalty is reduced by around $3 \mathrm{~dB}$.

\section{Coherent Crosstalk and External Phase Modulation}

The second method, spectral broadening at the CW source, is realized by applying external phase modulation. It enables much larger linewidth enhancement than the RSOA bias dithering. The same modulation frequency is applied as in the previous experiment. The difference in the experimental setup with respect to the setup for RSOA bias dithering is that instead of adding the phase modulation signal to the bias of the RSOA it is provided to the phase modulator inserted between the attenuator and the circulator, Fig. 7. Therefore, in this setup additional insertion loss introduced by the phase modulator has to be taken into account in the power budget of the link. This power loss is compensated by increasing the laser output power.

The phase shift in the phase modulator depends on the RF peak-to-peak voltage applied to the modulator. In the experiment we applied around $0.5,2.5$, and $4.5 \mathrm{~V}$ which corresponds to around $(1 / 4) \pi,(2 / 4) \pi$ and $(3 / 4) \pi$ phase shift, respectively,
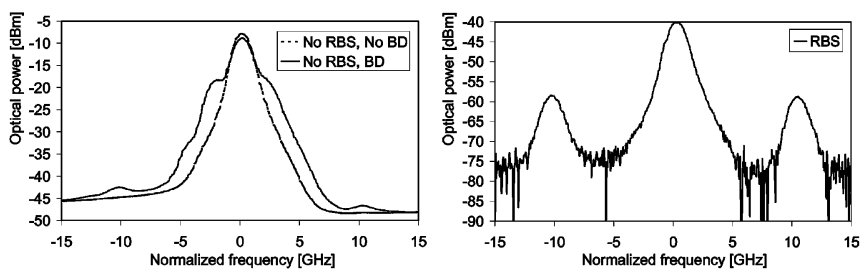

Fig. 12. Optical spectrum of the original $\mathrm{CW}$, backscattered signal, and spectrally broadened signal in the case of RSOA bias dithering.
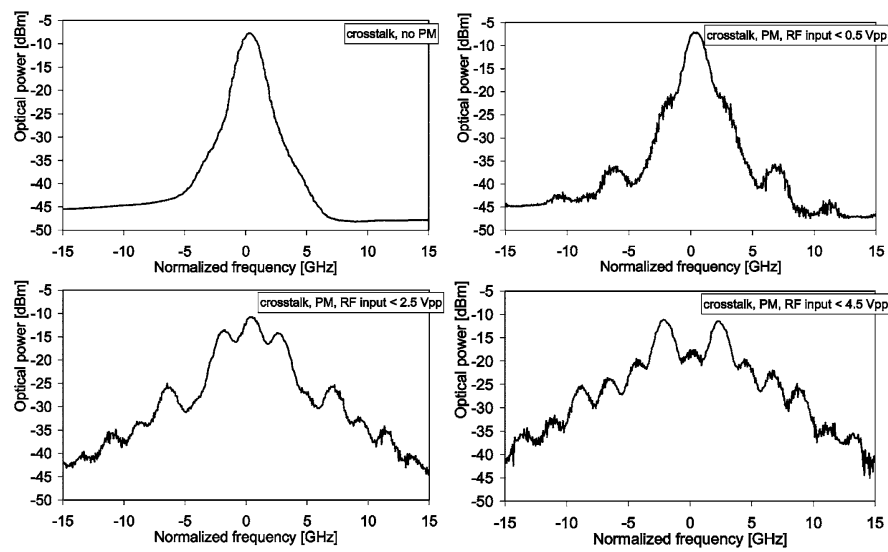

Fig. 13. Optical spectrum of the signals broadened by external phase modulation in the case of coherent crosstalk.

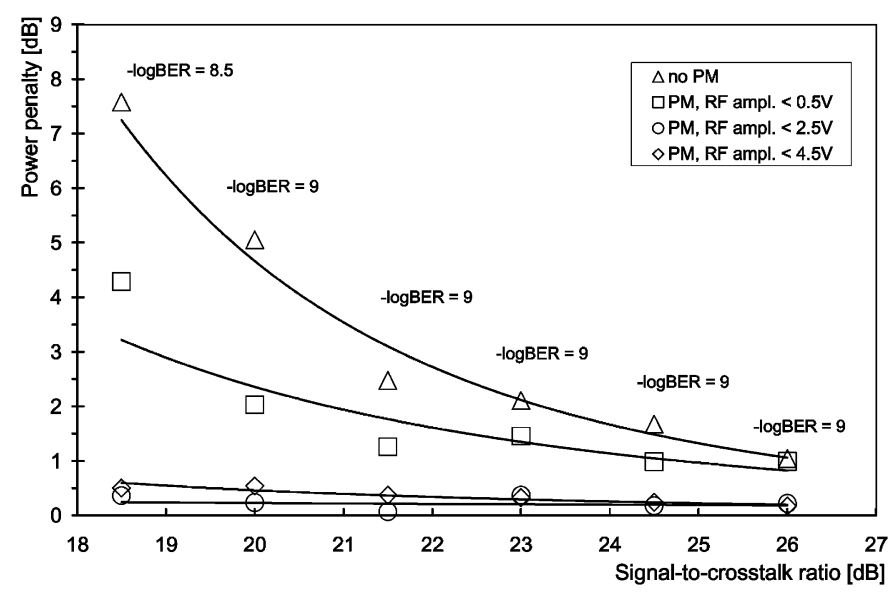

Fig. 14. Coherent crosstalk-induced power penalties with and without external phase modulation.

Fig. 13. For 2-4 V driving voltage up to $7 \mathrm{~dB}$ improvement in power penalty is achieved, Fig. 14.

In order to verify the relation between the phase modulation index and the modulator frequency as depicted in Fig. 6 and prove the applicability of the condition given in (22) an additional measurement is performed. The SNR of the received signal is measured at a constant SCR and constant phase modulation index for two cases: with and without $2.3 \mathrm{~m}$ of extra fiber between RSOA and the point of reflection, which changes the phase delay between the interfering signals, Fig. 15.

The minimum SNR when no extra fiber is applied is lower than the minimum SNR for the other case. This is because of two reasons: first, better SCR is achieved in the latter case, since 


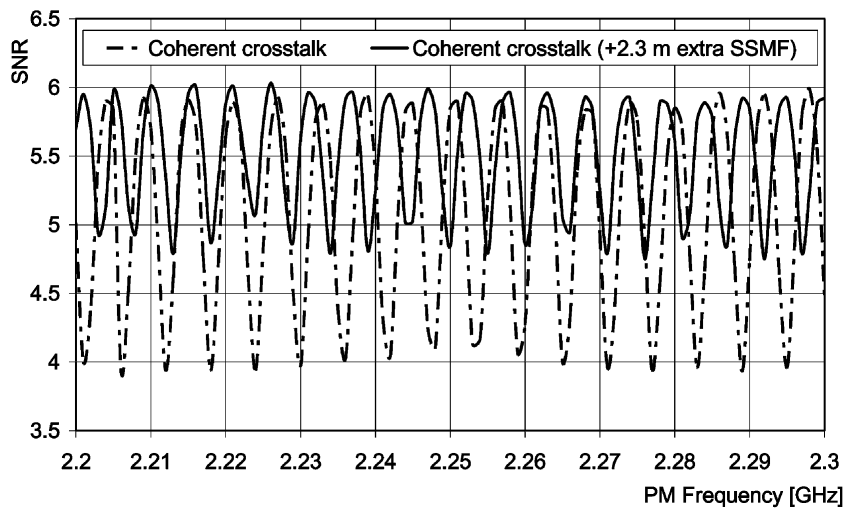

Fig. 15. SNR of the received signal in function of phase modulation frequency.

the return loss is around $1 \mathrm{~dB}$ higher. This is mainly due to additional connectors and, second, the phase relation is different. Phase difference can be lower and the CW light is slightly less coherent after a longer distance which means that the phase-induced power variations are smaller.

Both results in Fig. 15 show periodic behavior and the period is different in each case. This agrees with the mathematical model, which showed that the required amplitude of the $\mathrm{RF}$ signal provided to the external phase modulator is related to its frequency, (22). There, the calculation showed that for some specific frequencies (separated by an interval related to the optical phase delay) a higher RF amplitude is required, Fig. 6 .

The frequency interval for the case without extra fiber is $5.9 \mathrm{MHz}$, which gives the delay time $(\tau)$ of around $169.5 \mathrm{~ns}$. The refractive index of the applied fiber $(n)$ is 1.474 . According to $(25)$ the total distance $(2 d)$ where the reflected beam experiences the delay with respect to the $\mathrm{CW}$ input beam is $17.24 \mathrm{~m}$, which with respect to the roughly measured fiber $(17.50 \mathrm{~m})$ gives a reasonable result $(c=299792458(\mathrm{~m} / \mathrm{s})$ is the speed of light in vacuum and $d$ is the length of the fiber)

$$
2 d=\tau \frac{c}{n} .
$$

In the case with a longer fiber, the frequency interval in Fig. 15 is $5.1 \mathrm{MHz}(\tau=196.1 \mathrm{~ns})$, which gives the fiber length of $19.94 \mathrm{~m}$ (roughly measured value is $19.80 \mathrm{~m}$ ).

The difference between the calculated values (for a shorter and a longer fiber) is $2.70 \mathrm{~m}$, which corresponds to the value of $2.30 \mathrm{~m}$ of the extra fiber. This small discrepancy is due to the inaccuracy in estimating the delay based on the Fig. 15. However, this is enough to deduce that for some frequencies of phase modulation a higher phase modulation index is required and that if the optical delay between the interfering beam changes (due to, e.g., optical routing) either amplitude or frequency of phase modulation has to be adjusted.

The dips in Fig. 15 correspond to the peaks in Fig. 6 after matching the mathematical model, as has been achieved for the length of $17.28 \mathrm{~m}$ (shorter fiber, top graph in Fig. 16) and $19.94 \mathrm{~m}$ (longer fiber, bottom graph in Fig. 16) which respectively gives 0.22 and $0.14 \mathrm{~m}$ difference from the values derived from Fig. 15 due to the unknown value of LEF.
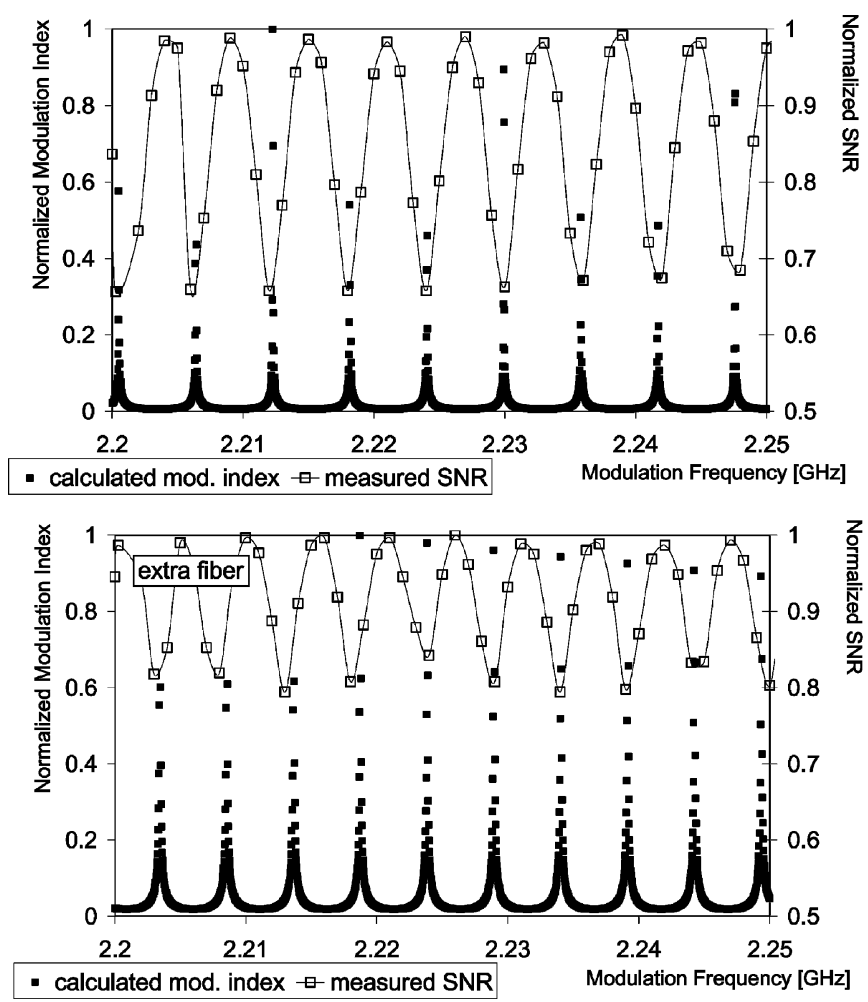

Fig. 16. Matching the mathematical model to the measurement results.
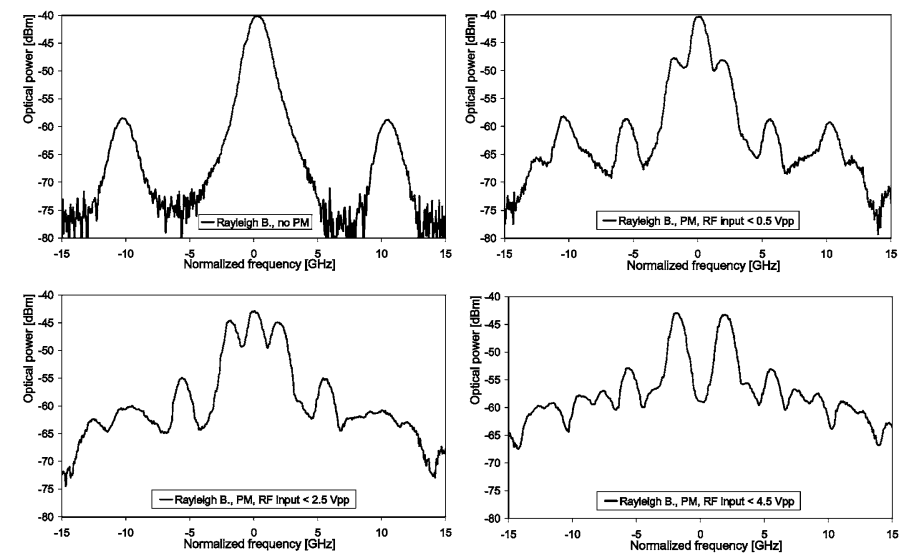

Fig. 17. Optical spectrum of the signals broadened by external phase modulation in case of incoherent crosstalk.

\section{Incoherent Crosstalk and External Phase Modulation}

A similar situation is under consideration here as in Section IV-B. In this case the interferer originates from the $25 \mathrm{~km}$ long SSMF, where the RBS accumulates. To combat the destructive influence on the useful signal, external phase modulation at the laser is applied as in Section IV-C. The spectrum of the backscattered signal changes for different phase modulation indices, Fig. 17.

The BER testing is performed for a single value of SCR equal to $18.5 \mathrm{~dB}$. The phase modulation frequency is $2.5 \mathrm{GHz}$ and the bitrate is $1.25 \mathrm{Gbit} / \mathrm{s}$. The results in Fig. 18 show that external phase modulation can effectively mitigate the incoherent crosstalk and reduce the power penalty from $5 \mathrm{~dB}$ down to $0.5 \mathrm{~dB}$. 


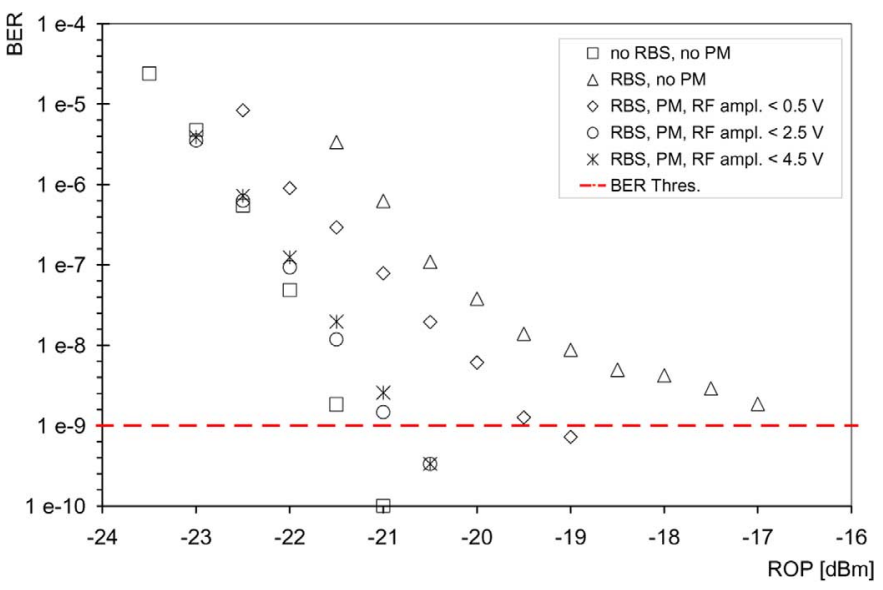

Fig. 18. BER results with and without external phase modulation in case of incoherent crosstalk.

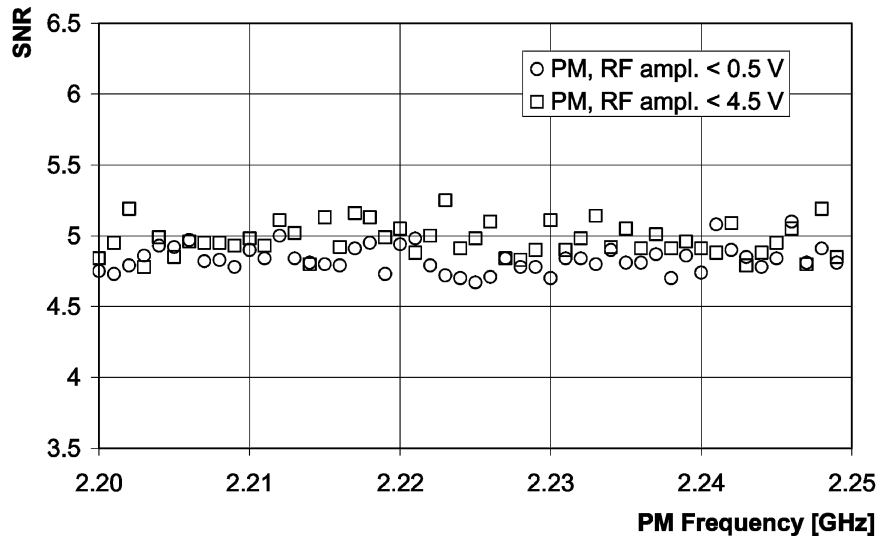

Fig. 19. SNR of the received signal in function of phase modulation frequency.

The SNR of the received signal is independent from phase modulation frequency, Fig. 19, which is in agreement with the predictions in Section III-D.

\section{DISCUSSION}

RSOA bias dithering and external optical phase modulation, show great potential in interferometric crosstalk mitigation by spectral linewidth broadening. These are compared in Fig. 20 for example value of SCR equal to $18.5 \mathrm{~dB}$ (coherent crosstalk).

A common disadvantage for both methods is that by occupying a larger optical bandwidth the adjacent channels are a subject to interchannel crosstalk in a WDM system. A further drawback is the increased sensitivity to dispersion. This is especially critical for large phase-modulated signals, which experience phase-to-amplitude conversion while propagating in dispersive media. Thus, the adjustment of phase modulation parameters has to be done in a deliberate manner taking into account channel spacing, fiber length and dispersion properties.

Coherent and incoherent types of crosstalk can be reduced by any of the mentioned techniques. The phase modulator is more efficient in spectral broadening than bias dithering in terms of required voltage. Applying $2 \mathrm{~V}$ of dithering amplitude to the RSOA does not bring as good results as around 2-V amplitude of driving voltage applied to the phase modulator. The difference between methods in terms of power penalty reduction is a

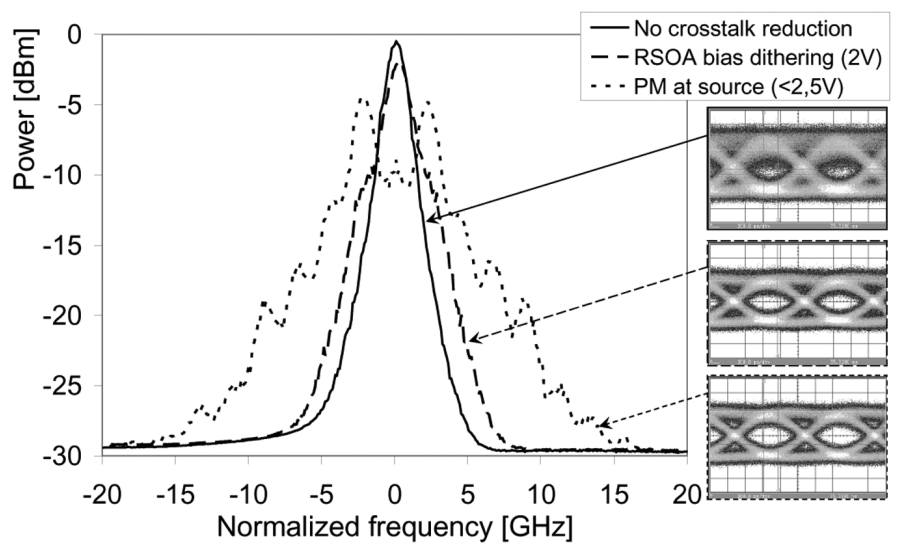

Fig. 20. Comparison of the two techniques in terms of spectral broadening and eye diagram improvement for coherent crosstalk.

$1.0 \mathrm{~dB}$ at $18.5 \mathrm{~dB}$ SCR for coherent crosstalk, when comparing Figs. 10 and 14, and $1.5 \mathrm{~dB}$ at the same SCR for incoherent crosstalk, when comparing Figs. 11 and 18. However, two kinds of penalty have to be paid when phase modulation is applied at the laser. The first is the requirement for extra hardware (a phase modulator) or the deployment of directly modulated laser at a frequency higher than the bit rate, and the second is the decrease in the power budget of the optical link if a phase modulator is applied. The latter may result in the reduction of split ratio in the passive optical network if no optical amplifiers are foreseen.

From the point of view of WDM-PON architecture external phase modulation at a source side is a cost-efficient solution, since a single phase modulator with a local oscillator can be used after a WDM multiplexer to provide the spectral broadening to all channels. we show in this paper that in case of coherent crosstalk due to the dependence of modulation index on the frequency of phase modulation this technique is not flexible (Fig. 15). This is because of the possible changes in optical delay between the interfering beams, which forces the readjustment of phase modulation frequency. Therefore, for the real network situation where the distances between $\mathrm{CO}$ and ONU may differ on a case by case basis, RSOA bias dithering is more advantageous. For this method there are no extra restrictions for phase modulation frequency apart from the requirement to set it out of the receiver bandwidth and within (or close to) the electrical bandwidth of the RSOA. The dithering amplitude boundaries are set by the maximum RSOA RF amplitude value, the electrical bandwidth of the RSOA (the dithering frequency has to be increased if it is out of 3-dB bandwidth of the RSOA) and the value of LEF which is depicted in Fig. 5.

By improving the tolerance to higher return power levels both methods can extend the reach of the optical link. Nevertheless, bias dithering seems to have some basic advantages over phase modulation at a source. It is an easy-to-implement sufficiently effective technique to mitigate interferometric crosstalk.

As a conclusion it is recommended that RSOA bias dithering technique is applied in the links where a danger of coherent crosstalk is high, e.g., short links between the RSOA and the adjacent network element. In case of RBS, or any other incoherent-type of crosstalk, which feeds back the RSOA phase modulation at the laser is more favourable. 


\section{SUMMARY}

In this paper, we have comprehensively presented two effective methods to mitigate the interferometric crosstalk in an access network employing RSOAs and centralized light generation. RSOA bias dithering is a novel method, which, to authors best knowledge, is in detail discussed for the first time here. External phase modulation is a method, which is well-known and very often applied in different types of optical links.

Both methods bring remarkable improvement in tolerance to low return loss of network components or high RBS-accumulated power. In the case of coherent crosstalk $(S C R=18.5 \mathrm{~dB})$ the power penalty was improved with $6 \mathrm{~dB}$ and $7 \mathrm{~dB}$ for RSOA bias dithering and external phase modulation, respectively. In the case of incoherent crosstalk $(S C R=18.5 \mathrm{~dB})$ the power penalty was improved with 3 and $4.5 \mathrm{~dB}$ for RSOA bias dithering and external phase modulation, respectively.

Mathematical predictions were experimentally confirmed and relative advantages of these techniques have been shown. Subsequently, they were compared in terms of effectiveness and implementation.

\section{REFERENCES}

[1] E. Iannone, "Passive optical networks must evolve to survive," Fibre Syst. Eur., pp. 26-27, Dec./Jan. 2008.

[2] A. M. J. Koonen, "Fiber to the home/fiber to the premises: What, where, and when?," Proc. IEEE, vol. 94, no. 5, pp. 911-934, May 2006.

[3] Y. Xiao, X. Du, J. Zhang, F. Hu, and S. Guizani, "Internet protocol television (IPTV): The killer application for the next-generation internet," IEEE Commun. Mag., vol. 45, no. 11, pp. 126-134, Nov. 2007.

[4] "Operators take on the FTTH challenge," Fibre Syst. Eur., pp. 21-24, Dec./Jan. 2008.

[5] P. J. Urban, B. Huiszoon, R. Roy, M. M. de Laat, F. M. Huijskens, E. J. Klein, G. D. Khoe, A. M. J. Koonen, and H. de Waardt, "High bit rate dynamically reconfigurable WDM/TDM access network," IEEE/OSA J. Opt. Commun. Netw., vol. 1, no. 2, pp. A143-A159, Jul. 2009.

[6] F.-T. An, K. S. Kim, D. Gutierrez, S. Yam, E. Hu, K. Schrikhande, and L. G. Kazovsky, "SUCCESS: A next generation hybrid WDM/TDM optical access network architecture," J. Lightw. Technol., vol. 22, no. 11, pp. 2557-2569, Nov. 2004.

[7] A. R. Dhaini, C. M. Assi, M. Maier, and A. Shami, "Dynamic wavelength and bandwidth allocation in hybrid TDM/WDM EPON networks," J. Lightw. Technol., vol. 25, no. 1, pp. 277-286, Jan. 2007.

[8] J. Prat, E. B. Pere, M. G. Joan, and D. Oscar, Fiber-to-the-Home Technologies. Dordrecht, The Netherlands: Kluwer, 2002.

[9] E. Wong et al., "Directly modulated self-seeding reflective semicondctor optical amplifiers as colorless transmitters for wavelength division multiplexed passive optical networks," J. Lightw. Technol., vol. 25, no. 1, pp. 67-74, Jan. 2007.

[10] E. J. Klein, P. J. Urban, G. Sengo, L. T. H. Hilderink, M. Hoekman, R. Pellens, P. van Dijk, and A. Driessen, "Densely integrated microring resonator based photonic devices for use in access networks," Opt. Exp., vol. 15, no. 16, pp. 10 346-10 355, Aug. 2007.

[11] L. Xu, X. J. M. Leijtens, M. J. H. Sander-Jochem, T. de Vries, Y. S. Oei, P. J. van Veldhoven, and R. N. K. Smit, "InP based polarization insensitive tunable duplexer and integrated reflective transceiver," in Proc. ECIO, pp. $1-4$.

[12] T. Kamalakis and T. S. Sagriotis, "Accurate estimation of the error probability in the presence of in-band crosstalk noise in WDM networks," J. Lightw. Technol., vol. 21, no. 10, pp. 2172-2181, Oct. 2003.

[13] A. Banerjee, Y. Park, F. Clarke, H. Song, S. Yang, G. Kramer, K. Kim, and B. Mukherjee, "Wavelength-division-multiplexed passive optical network (WDM-PON) technologies for broadband access: A review [Invited]," OSA J. Opt. Netw., vol. 4, no. 11, pp. 737-758, Oct. 2005.
[14] Y. Shen, K. Lu, and W. Gu, "Coherent and icoherent crosstalk in WDM optical networks," J. Lightw. Technol., vol. 17, no. 5, pp. 759-764, May 1999.

[15] P. J. Legg, M. Tur, and I. Andonovic, "Solution paths to limit interference noise induced performance degradation in ASK/direct detection lightwave networks," J. Lightw. Technol., vol. 14, no. 9, pp. 1943-1954, Sep. 1996.

[16] R. Khosravani, M. I. Hayee, and B. H. E. Willner, "Reduction of Coherent Crosstalk in WDM Add/Drop Multiplexing Nodes by Bit Pattern Misalignment," IEEE Photon. Technol. Lett., vol. 11, no. 1, pp. 134-136, Jan. 1999.

[17] P. J. Urban, A. M. J. Koonen, G. D. Khoe, and H. de Waardt, "Coherent crosstalk-suppression in WDM access networks employing reflective semiconductor optical amplifiers," in Proc. IEEE ECOC, vol. 3, pp. 91-92.

[18] P. J. Urban, A. M. J. Koonen, G. D. Khoe, and H. de Waardt, "Mitigation of reflection-induced crosstalk in a WDM access network," presented at the OFC, OThT3.

[19] P. J. Urban, A. M. J. Koonen, G. D. Khoe, and H. de Waardt, "Rayleigh backscattering-suppression in a WDM access network employing a reflective semiconductor optical amplifier," in Proc. IEEE/LEOS Benelux Symp., pp. 147-150.

[20] H. Kim, H. C. Li, and C. H. Kim, "Effects of intraband crosstalk on incoherent light using SOA-based noise sppression technique," IEEE Photon. Technol. Lett., vol. 18, no. 7, pp. 1542-1544, Jul. 2006.

[21] M. Fujiwara, J.-I. Khani, H. Suzuki, and K. Iwatsuki, "Impact of backreflection on upstream transmission in WDM single-fiber loopback access networks," J. Lightw. Technol., vol. 24, no. 2, pp. 740-746, Feb. 2006.

[22] H. W. Hu and H. Anis, "Degradation of bi-directional single fiber transmission in WDM-PON due to beat noise," J. Lightw. Technol., vol. 26, no. 8, pp. 870-881, Apr. 2008.

[23] Y. J. Lee, Y. Cho, A. Murakami, A. Agata, Y. Takushima, and Y. C. Chung, "Reflection Tolerance of RSOA-based WDM PON," in Proc. OECC/IOOC, pp. 102-103, paper 11A1-4.

[24] G. P. Agrawal and N. A. Olson, "Self-phase modulation and spectral broadening of optical pulses in semiconductor laser amplifiers," IEEE J. Quant. Electron., vol. 25, no. 11, pp. 2297-2306, Nov. 1989.

[25] A. Yariv, H. Blauvelt, D. Huff, and H. Zarem, "An experimental and theoretical study of the suppression of interferometric noise and distortion in AM optical links by phase dither," J. Lightw. Technol., vol. 15, no. 3, pp. 437-443, Mar. 1997.

[26] M. Sharma, H. Ibe, and T. Ozeki, "WDM ring network using a centralized multiwavelength light source and add-drop multiplexing filters," J. Lightw. Technol., vol. 15, no. 6, pp. 917-929, Mar. 1997.

[27] K. Inoue, "Suppression of influence of homowavelength crosstalk in an optical add/drop multiplexing system by modulating LD light frequency," IEEE Photon. Technol. Lett., vol. 11, no. 9, pp. 1177-1179, Sep. 1999.

[28] E. Tangdiongga, I. T. Monroy, R. Jonker, and H. de Waardt, "Experimental evaluation of optical crosstalk mitigation using phase scrambling," IEEE Photon. Technol. Lett., vol. 12, no. 5, pp. 567-569, May 2000.

[29] W.-S. Jang, H.-C. Kwon, and S.-K. Han, "Sppression of Rayleigh backscattering in a bidirectional WDM optical link using clipped direct modulation," IEE Proc.-Optoelectron., vol. 151, no. 4, pp. 219-222, Aug. 2004.

[30] P. J. Urban, E. J. Klein, L. Xu, E. G. C. Pluk, A. M. J. Koonen, G. D. Khoe, and H. de Waardt, "1.25-10 Gbit/s reconfigurable access network architecture," presented at the ICTON, paper Th.B1.6.

[31] P. J. Urban, E. G. C. Pluk, M. M. de Laat, F. M. Huijskens, G. D. Khoe, A. M. J. Koonen, and H. de Waardt, "1.25-Gb/s transmission over an access network link with tunable OADM and a reflective SOA," IEEE Photon. Technol. Lett., vol. 21, no. 3, pp. 380-382, Mar. 2009.

[32] L. Occhi, L. Schares, and G. Guekos, "Phase modeling based on the alpha-factor in bulk semiconductor optical amplifiers," IEEE J. Sel. Top. Quant. Electron., vol. 9, no. 3, pp. 788-797, May/Jun. 2003.

[33] P. K. Pepeljugoski and K. Y. Lau, "Interferometric noise reduction in fiber-optic links by superposition of high frequency modulation," IEEE J. Lightw. Technol., vol. 10, no. 7, pp. 957-963, Jul. 1992.

[34] G. P. Agrawal, Fiber-Optic Communication Systems. New York: Wiley, 2002

[35] RSOA datasheet (Device No. 02852), Centre for Integrated Photonics. 


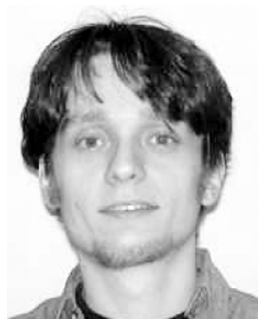

Patryk J. Urban (S'05) was born in Szczecin, Poland, in 1981. He received the M.Sc. degree in electrical engineering from the Department of Electrical Engineering, Szczecin University of Technology, in 2004, where he was also a student assistant in 2003 to 2005 in the Optical Telecommunication and Photonics Group. In 2004, he began doctoral studies at Szczecin University of Technology in the field of nonlinear optics. In 2005, he joined the COBRA Research Institute at the Eindhoven University of Technology, The Netherlands, and changed the subject of his Ph.D. research to WDM/TDM access networks.

He is currently involved in research on next-generation broadband access network architectures involving network reconfigurability and bandwidth on-demand provision.

Mr. Urban acts as a reviewer for the IET Electronics Letters and the IEEE Photonics TeChNOLOGy LetTers. From 2006-2008, he was a member of the IEEE/LEOS Benelux Student Chapter Board co-organizing IEEE LEOS Benelux Annual Workshops.

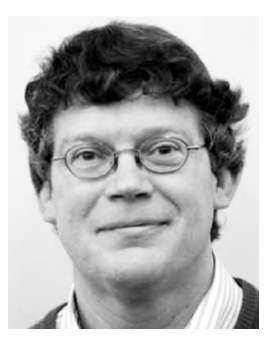

A. M. J. Koonen (M'00-SM'01-F'07) received the M.Sc. (cum laude) degree in electrical engineering from the Eindhoven University of Technology, Eindhoven, The Netherlands, in 1979.

He was with Bell Laboratories in Lucent Technologies as a Technical Manager of applied research for more than 20 years. He was a part-time Professor at Twente University, Enschede, The Netherlands, from 1991 to 2000. Since 2001, he has been a Full Professor at the Eindhoven University of Technology in the Electro-optical Communication Systems Group at the COBRA Institute, where he has been the Chairman of this group since 2004. His current research interests include broadband fiber access and in-building networks, radio-over-fiber networks, and optical packet-switched networks. He has initiated and led several European and national R\&D projects in this area on dynamically reconfigurable hybrid fiber access networks, fiber-wireless, packet-switched access, and short-range multimode (polymer) optical fiber networks, and label-controlled optical packet routed networks. Currently, he is involved in a number of access/in-home projects in the Dutch Freeband program, the Dutch IOP Generieke Communicatie program, and the EC FP6 IST and FP7 ICT programs. He has authored and coauthored more than 250 conference and journal publications.

Prof. Koonen has been a Bell Laboratories Fellow since 1998 and a member of the LEOS Board of Governors since 2007.

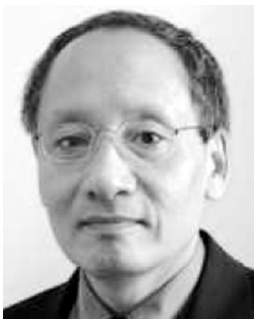

G. Djan Khoe (F'91) received the degree of Elektrotechnisch Ingenieur (cum laude) from the Eindhoven University of Technology, Eindhoven, The Netherlands, in 1971.

He decided to start research at the Dutch Foundation for Fundamental Research on Matter (FOM) Laboratory on Plasma Physics, Rijnhuizen. In 1973 , he joined Philips Research Laboratories to start research in the area of optical fiber communication systems. In 1983, he was appointed to part-time Professor at Eindhoven University of Technology. He became a Full Professor at the same university in 1994 and is currently Chairman of the Department of Telecommunication Technology and Electromagnetics (TTE). Most of his work has been devoted to single-mode fiber systems and components. Currently, his research programs are centered on ultrafast all-optical signal processing, high capacity transport systems and systems in the environment of the users. He has more than 40 United States Patents and has authored and coauthored more than 150 papers, invited papers, and chapters in books. His professional activities include many conferences, where he has served on technical committees, management committees, and advisory committees as a member or chairman. He has been involved in journal activities, as associate editor, as a member of the advisory board or as reviewer In Europe, he is closely involved in Research Programs of the European Community and in Dutch national research programs, as participant, evaluator, auditor, program committee member, and as member of the steering committee. $\mathrm{He}$ is one of the founders of the Dutch COBRA University Research Institute In 2001, he brought four European groups together to start a new international alliance called the European Institute on Telecommunication Technologies (eiTT).

Dr. Khoe is one of the three recipients of the prestigious "Top Research Institute Photonics" grant that was awarded to COBRA in 1998 by the Netherlands Ministry of Education, Culture, and Science. He has served in the IEEE/LEOS organization as European Representative in the BoG, VP Finance \& Administration, VP Membership, BoG Elected Member, President and member of the Executive Committee of the IEEE Benelux Section. He was founder of the LEOS Benelux Chapter. He has been an OSA Fellow since 2006 and received the MOC/GRIN award in 1997.

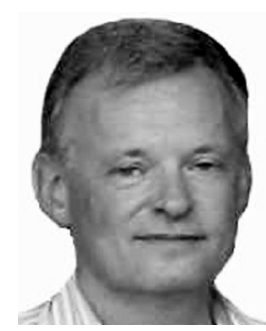

Huug de Waardt (M'05) was born in Voorburg, The Netherlands, in December, 1953. He received the M.Sc.E.E. and the Ph.D. degrees from the Delft University of Technology, Delft, The Netherlands, in 1980 and 1995 , respectively.

In 1981, he started his professional career in the Physics Department at PTT Research in Leidschendam, The Netherlands, where he worked on the performance issues of optoelectronic devices. In 1989, he moved to the Transmission Department and became involved in WDM high-bit-rate optical transmission. In 1995, he was appointed as an Associated Professor at the Eindhoven University of Technology (TU/e), Eindhoven, The Netherlands, in the area of high-capacity trunk transmission. He coordinated the participation of TU/e in ACTS Upgrade, ACTS BLISS, ACTS APEX, and IST FASHION. Presently, he serves as project leader of the national research initiative Freeband Broadband Photonics (2004-2008). His current interests are in high capacity optical transmission and networking, integrated optics, and semiconductor optical amplifiers/modulators. He has (co)authored over 150 conference and journal papers. 